\title{
ANALYSIS OF THE 11-YEAR RECORD (1987-1997) OF AIR POLLUTION MEASUREMENTS IN ATHENS, GREECE. PART I: PRIMARY AIR POLLUTANTS
}

\author{
P. D. KALABOKAS ${ }^{1 *}$, \\ L. G. VIRAS ${ }^{2}$, \\ C. C. REPAPIS 1
}

Received: 16/09/99

Accepted: 25/11/99

\author{
${ }^{1}$ Academy of Athens, Research Center for Atmospheric \\ Physics and Climatology, 131, Tritis Septemvriou, str., 11251 Athens, Greece \\ ${ }^{2}$ Ministry of Environment, Directorate of Air and Noise Pollution Control, \\ 147, Patission str., 11251 Athens, Greece
}

*to whom all correspondence should be addressed

\begin{abstract}
A climatological analysis of atmospheric concentrations of primary air pollutants in Athens, Greece, is presented for the 11-year period 1987-1997, since the automated local air pollution network operating by the Ministry of Environment started to record all conventional pollutants. The concentration levels of the atmospheric pollutants carbon monoxide, nitrogen oxides, sulfur dioxide and black smoke for the most polluted stations (Patission, Athinas and Piraeus) of the air pollution network were examined. For all primary pollutants a seasonal variation with minimum in summer and maximum in winter is observed. Sulfur dioxide has the strongest seasonal cycle and black smoke the weakest. There is a significant downward trend for almost all pollutants in all stations. The highest reductions are observed in Patission where a comparison between the 3-year periods 1988-1990 and 1995-1997 gives 52\%, 34\%, $26 \%$ and $20 \%$ decreases for sulfur dioxide, carbon monoxide, nitrogen oxides and black smoke, respectively. The pollution abatement measures taken by the state authorities during the period 1990-1994, mainly consisting in the replacement of the old technology gasoline-powered private cars and the reduction of the sulfur content in diesel oil, seem to be the primary cause of the improvement in air quality in Athens during the recent years.
\end{abstract}

KEY WORDS: Air pollution, Urban air pollutants, Athens

\section{INTRODUCTION}

During the last twenty-five years air pollution in Athens, Greece, became a priority issue for the authorities and at the same time subject of many research studies (Lalas et al., 1987; Mantis et al., 1992; Viras and Siskos, 1992; Kallos et al., 1993; Kassomenos et al., 1995; Ziomas et al., 1995; Ziomas et al., 1998, among others). A critical factor contributing to the creation of the urban smog or the so-called "nephos" in Athens, is the high population density ( 3.5 million people are confined in an area of $450 \mathrm{~km}^{2}$ ) associated with intense polluting anthropogenic activities (50\% of the national vehicle fleet and $40 \%$ of the industrial activity together with the nearby Thriassion Plain). Other relevant factors are the local topography with relatively high mountains (up to $1500 \mathrm{~m}$ ) surround- 
ing the basin and causing poor ventilation, the frequent appearance of sea breeze, and finally the high levels of solar irradiation with the subsequent formation of photochemical pollutants from the transformation of the emitted oxides of nitrogen and hydrocarbons.

The main pollution sources in the Athens Greater area are automobile traffic, industry and central heating. On a yearly basis traffic is considered to be the main source of carbon monoxide $(\mathrm{CO})$, nitrogen oxides $\left(\mathrm{NO}_{\mathrm{X}}\right)$, black smoke (BS) and hydrocarbons, while industry is the main source for sulfur dioxide $\left(\mathrm{SO}_{2}\right)$ and suspended particles (Katsoulis, 1996; Viras and Siskos, 1992; Arvanitis et al., 1997). But if only the cold period of the year (November-April) is considered, central heating becomes the most important pollution source of $\mathrm{SO}_{2}$, while it has the same importance in smoke emissions as car traffic, which is clearly the most important source of smoke for the rest of the year.

An important factor concerning automobile pollution is the steady increase in the number of private cars in Athens, which constitute the most important source of car traffic, with an average rate of about $6 \%$ per year (Alexopoulos et al., 1993; MinEnv report, 1998b). After 1991, the increase concerns only new technology "clean" cars using unleaded gasoline and equipped with three-way catalysts in their exhausts, but the old technology cars using leaded gasoline were still the majority in 1997. Concerning the other vehicle categories, motorcycles are using mostly gasoline, while taxis and buses are using diesel oil with low sulfur content.

Among the important industrial units located in the Athens basin and its surrounding area (including Thriassion plain) are two refineries, one fertilizer plant, two iron steel plants and one cement plant. There are also about 100 mediumsized industries, mainly in food processing, plastic and textile products. Industrial plants in the basin are concentrated along a SW-NE axis, which includes the western quarters of the city and also in the central parts of Athens and Piraeus (Katsoulis, 1996).

Central heating in Athens consumes diesel oil and is operating from November through April.

Examining the most characteristic contributions of various pollution sources to specific air pollutants based on pollution estimates, it is apparent that road traffic contributes significantly to the overall Athenean emissions. On a yearly basis, practically all $\mathrm{CO}$ emissions, $3 / 4$ of $\mathrm{NO}_{\mathrm{x}}$ and hydrocarbon emissions, and nearly $2 / 3$ of BS emissions are associated with road traffic, and especially the private passenger cars. On the other hand, all particulate emissions and more than $2 / 3$ of $\mathrm{SO}_{2}$ emissions are associated with industrial activity. Finally, about $1 / 5$ of $\mathrm{SO}_{2}$ and $\mathrm{BS}$ emissions are estimated to originate from central heating (Viras and Siskos, 1992; Katsoulis, 1996; Arvanitis et al., 1997). But if the cold period of the year is separately examined, then a little more than the half of the emitted $\mathrm{SO}_{2}$ originates from central heating, while the contribution of BS from this activity doubles in comparison to its yearly average and becomes equally important with the BS share of traffic emissions (about $40 \%$ ). Finally, during the warm period of the year (May to October) more than 3/4 of BS, $\mathrm{NO}_{\mathrm{x}}$ and hydrocarbons are emitted from road traffic as well as $90 \%$ of $\mathrm{SO}_{2}$.

The climate of Athens is typically Mediterranean with hot dry summers and wet mild winters. The mean daily summer and winter temperatures are $25.8^{\circ} \mathrm{C}$ and $10.1^{\circ} \mathrm{C}$, respectively. The mean annual total precipitation height is about $400 \mathrm{~mm}$, and $85 \%$ of it occurs from October to March. The mean wind pattern in the atmospheric boundary layer in Athens during the warmer part of the year is a persisted northeasterly flow of relatively high constancy. The Athens basin is exposed to the summer monsoon circulation of the Eastern Mediterranean. The resulting northerly winds in the Aegean, the "Etesians" winds, are occasionally interrupted by the passage of weak pressure troughs (Repapis et al., 1975). In this case, the normally weak southwesterly seabreeze circulation is intensified and reaches deep in the Athens basin, a situation associated with high accumulations of air pollutants and eventually severe photochemical pollution episodes. The sea-breeze circulation in Athens is developed mostly during days of the warm period of the year with weak pressure patterns. The sea-breeze tends to stratify the atmosphere above the city, trapping air pollutants in a relatively small height above ground. Significant chemical transformations of photochemical precursors may also occur in the course of this circulation. Sea-breeze circulation can be developed during more than $30 \%$ of 


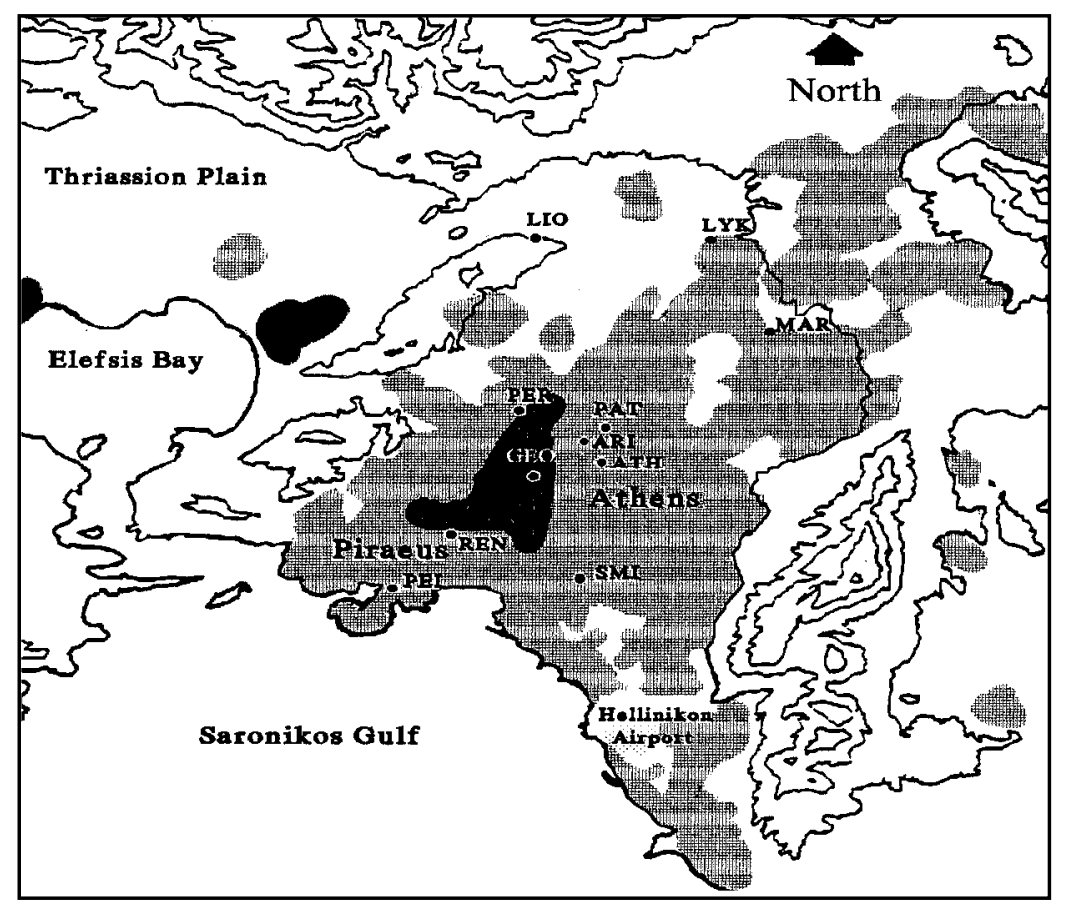

Figure 1. Map of the Greater Athens area with elevation contours at $200 \mathrm{~m}$ intervals. The industrial area (dark shaded) and the urban area (light shaded) are indicated more pollutants. In 1987 the set of the continuously monitored substances was completed with the addition of $\mathrm{NO}$ and $\mathrm{O}_{3}$, bringing the total number of systematically measured pollutants to six $\left(\mathrm{CO}, \mathrm{NO}_{2}, \mathrm{SO}_{2}\right.$, $\mathrm{BS}, \mathrm{NO}, \mathrm{O}_{3}$ ). In this work, the 11-year period 1987-1997, during which the entire set of pollutants was recorded, will be examined.

\section{RESULTS AND DISCUSSION}

In Table 1 the average atmospheric concentrations of the primary pollutants for the main stations of the air pollution monitoring network in Athens for the 11-year period 1987-1997 are presented. It can be easily deduced that the concentrations of the first 3 stations (Patission, Athinas and Piraeus), which are located in heavily polluted urban the days in the spring and summer months in Athens (Prezerakos, 1986). Air pollution episodes may occur in Athens during all seasons of the year but most of these episodes are associated with the development of sea-breeze (Kallos et al., 1993).

The air pollution monitoring network of the Greater Athens area consists of 10 stations (Fig. 1). The first measurements of air pollutants in Athens started in the '70s and the network was gradually expanded including more stations and sites in the center of Athens and Piraeus, are significantly higher than the rest of the stations. For this reason these three stations will be examined systematically in this work, considering that their characteristic features are the determining factor for the assessment of air quality levels in urban Athens. The highest values are observed in Patission station for all pollutants. Athinas and Piraeus stations follow with comparative pollution levels. In general, the average pollution levels in Athinas are higher than in Piraeus reflect-

Table 1: Average yearly atmospheric concentrations of urban air pollutants for the main stations of the air pollution monitoring network in Athens for the 11-year period 1987-1997 (mean value \pm standard deviation)

\begin{tabular}{|c|c|c|c|c|c|}
\hline & $\mathrm{CO}\left(\mu \mathrm{g} / \mathrm{m}^{-3}\right)$ & $\mathrm{NO}\left(\mu \mathrm{g} / \mathrm{m}^{-3}\right)$ & $\mathrm{NO}_{2}\left(\mu \mathrm{g} / \mathrm{m}^{3}\right)$ & $\mathrm{SO}_{2}\left(\mu \mathrm{g} / \mathrm{m}^{3}\right)$ & $\mathrm{BS}\left(\mu \mathrm{g} / \mathrm{m}^{3}\right)$ \\
\hline Patission & $6.2 \pm 1.2$ & $172 \pm 24$ & $108 \pm 10$ & $64 \pm 19$ & $111 \pm 25$ \\
\hline Athinas & $3.8 \pm 0.5$ & $90 \pm 10$ & $80 \pm 8$ & $41 \pm 13$ & $47 \pm 9$ \\
\hline Piraeus & $3.5 \pm 0.9$ & $66 \pm 9$ & $72 \pm 7$ & $51 \pm 16$ & $45 \pm 12$ \\
\hline Geoponiki & $1.6 \pm 0.3$ & $56 \pm 16$ & $53 \pm 10$ & $24 \pm 6$ & $29 \pm 5$ \\
\hline Peristeri & $2.4 \pm 0.7$ & $52 \pm 14$ & $58 \pm 10$ & $25 \pm 5$ & $30 \pm 8$ \\
\hline Smyrni & $1.8 \pm 0.2$ & $31 \pm 5$ & $43 \pm 8$ & $31 \pm 11$ & $26 \pm 5$ \\
\hline Maroussi & $1.9 \pm 0.6$ & $39 \pm 22$ & $35 \pm 7$ & $16 \pm 1$ & $21 \pm 1$ \\
\hline Liossia & & $17 \pm 8$ & $29 \pm 5$ & $23 \pm 11$ & \\
\hline
\end{tabular}




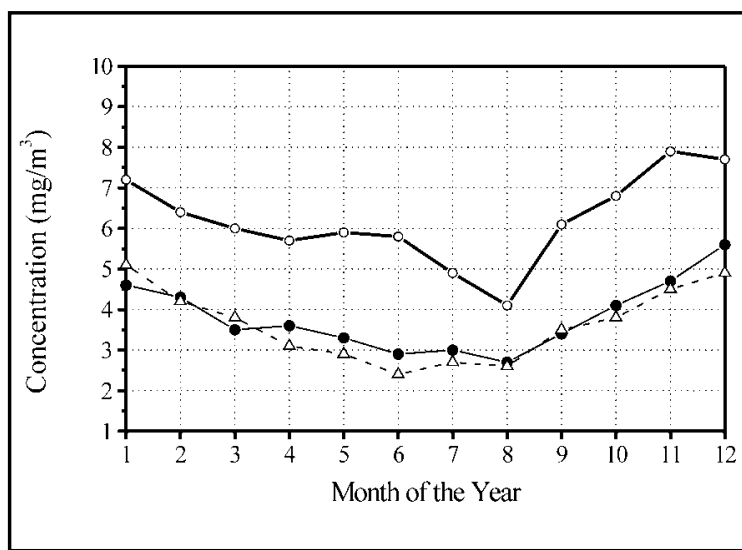

Figure 2. Seasonal variation of CO in Athens for 1987-1997 for the stations of Patission (bold solid line), Athinas (solid line) and Piraeus (dashed line)

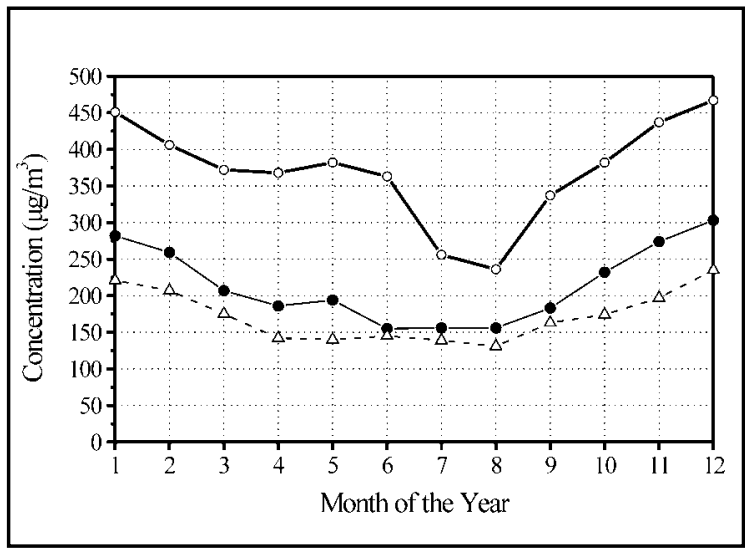

Figure 3. Seasonal variation of $\mathrm{NO}_{\mathrm{X}}$ in Athens for 1987-1997 for the stations of Patission (bold solid line), Athinas (solid line) and Piraeus (dashed line)

ing the heavier traffic load in the center of Athens. The only pollutant which has higher concentrations in Piraeus is $\mathrm{SO}_{2}$, due probably to the activities in the neighboring industrial area as well as to the nearby harbor, which constitute additional pollution sources close to this measuring site in comparison to the other two stations.

In figures $2,3,4,5$ the seasonal variation of the primary pollutant mean monthly concentrations, based on mean monthly values, is examined. Because of the very rapid chemical conversion of the emitted $\mathrm{NO}$ to $\mathrm{NO}_{2}$, mainly because of the fast reaction with $\mathrm{O}_{3}$ which is usually in excess, both substances are treated together as a single primary pollutant $\mathrm{NO}_{\mathrm{X}}$. For uniformity pur-

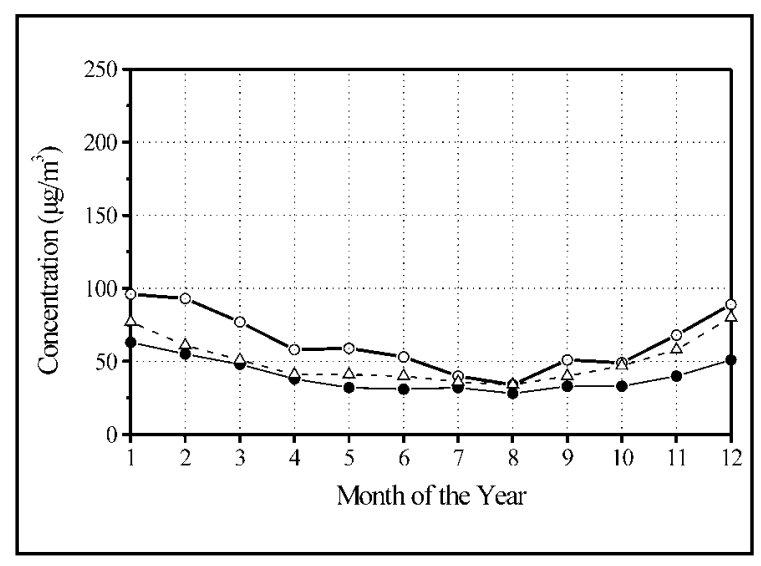

Figure 4. Seasonal variation of $\mathrm{SO}_{2}$ in Athens for 1987-1997 for the stations of Patission (bold solid line), Athinas (solid line) and Piraeus (dashed line)

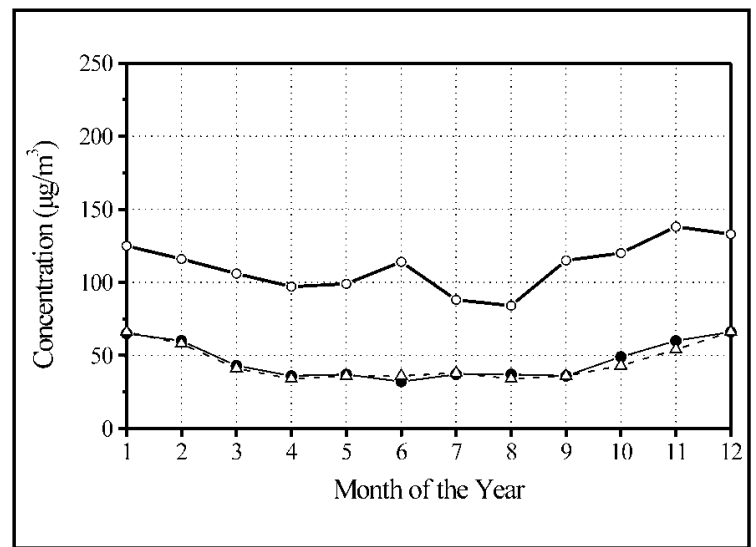

Figure 5. Seasonal variation of BS in Athens for 19871997 for the stations of Patission (bold solid line), Athinas (solid line) and Piraeus (dashed line)

poses, $\mathrm{NO}$ is converted to $\mathrm{NO}_{2}$ and the unit used is $\mu \mathrm{g} / \mathrm{m}^{3}$ "NO${ }_{2}$ equivalent". The existing chemical losses of the gaseous pollutants $\mathrm{CO}, \mathrm{NO}_{2}$ and $\mathrm{SO}_{2}$, due especially to their reactions with the $\mathrm{OH}$ radical (Finlayson-Pitts and Pitts, 1986), are considered as minor on a daily time-scale in comparison to the emission and atmospheric dispersion factor. Therefore, the $\mathrm{CO}, \mathrm{NO}_{\mathrm{x}}$ and $\mathrm{SO}_{2}$ are treated as chemically inert substances. For all examined pollutants a strong seasonal variation is observed with maxima in winter months and minima in summer months. The curves of $\mathrm{CO}$ and $\mathrm{NO}_{\mathrm{X}}$ show quite the same pattern indicating major influence from the same source (car traffic). The average winter levels are by about 50 - 


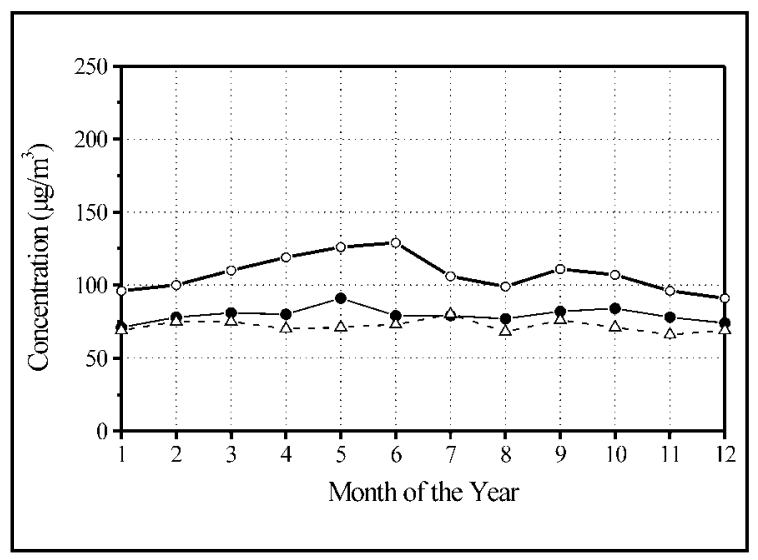

Figure 6. Seasonal variation of $\mathrm{NO}_{2}$ in Athens for 1987-1997 for the stations of Patission (bold solid line), Athinas (solid line) and Piraeus (dashed line)

$70 \%$ higher than the summer ones. The summer minimum for all pollutants is due to the reduced activity in the city, mainly in car traffic, as a result of summer vacations in July-August, but is also enhanced by the better dispersion conditions due to the strong "Etesian" winds. The seasonal variation of $\mathrm{NO}_{\mathrm{X}}$ is due almost exclusively to $\mathrm{NO}$, as the summer values of $\mathrm{NO}_{2}$ are almost similar with the winter ones (fig. 6). During summer, although NO concentration is lower than the winter one, the photochemical transformation from NO to $\mathrm{NO}_{2}$ is more intense. This explains the almost similar values of $\mathrm{NO}_{2}$ in winter and summer and the high $\mathrm{NO}_{2}$ values in late spring and early summer, during which the city activity has not yet been reduced and the "Etesian" winds are not yet strong. On the other hand, $\mathrm{SO}_{2}$ has the most important seasonal variation, and the average winter/summer ratio is greater than a factor of two in Patission. Emissions from central heating are responsible for the high winter levels of $\mathrm{SO}_{2}$. In Athinas the ratio between winter and summer $\mathrm{SO}_{2}$ levels is significantly lower than in Patission and is approaching the corresponding ratios observed for $\mathrm{CO}$ and $\mathrm{NO}_{\mathrm{X}}$. This can be justified by the fact that the character of this station is more commercial than residential, and therefore central heating is not used in the late evening and night hours where the highest daily values are usually observed (Paliatsos, 1998). In contrast to $\mathrm{SO}_{2}$, black smoke shows the less marked seasonal cycle with winter average values only $20-30 \%$ higher than the summer ones. A possible reason

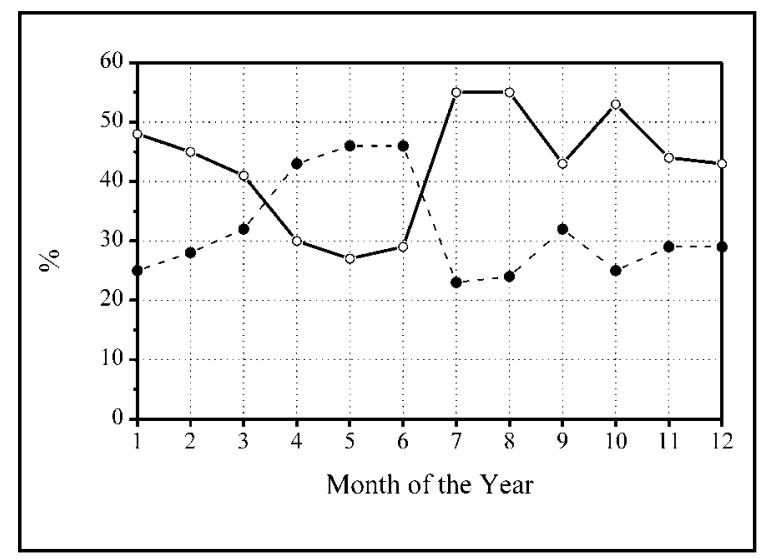

Figure 7. Seasonal variation of the frequency of appearance of northern (bold solid line) and southern winds (dashed line) in Athens for 1987-1997

is that one of the main sources of BS are dieselpowered vehicles like the public transportation buses, taxis and heavy duty-trucks. This vehicle category is not expected to show the same significant circulation decrease in summer as that observed for the private passenger cars.

The station of Patission exhibits for all months significantly higher concentrations relatively to the other two stations for all examined pollutants, in general about a factor of two. The only exception is for $\mathrm{SO}_{2}$, where the average monthly values of Piraeus are almost comparable with the values of Patission, especially in the second half year. It should be mentioned at this point that the relative standard deviations of the 11-year mean monthly values in all three stations vary in the order of $20 \%$ for $\mathrm{CO}$ and $\mathrm{NO}_{\mathrm{x}}$ and in the order of $30-35 \%$ for $\mathrm{BS}$ and $\mathrm{SO}_{2}$.

For the Athens basin an important meteorological parameter controlling the atmospheric dispersion of pollutants, especially during the warm period of the year, is the relative frequency of northern and southern winds, which is presented in figure 7 (data of the National Observatory of Athens). As mentioned above, the northern sector winds (directions $\mathrm{N}, \mathrm{NNE}, \mathrm{NE}, \mathrm{ENE}$ ) in the summer are mainly the strong local winds (the "Etesians"), which are associated with better dispersion conditions (Repapis et al., 1975). On the other hand, the southern winds (S, SSW, SW, WSW) are, in general, developing during the warm period sea-breeze in the Saronicos Gulf associated with a more frequent appearance of 
low night temperature inversions (Lalas et al., 1987). This situation is not valid for the winter months, where southern winds are normally associated with front passage. For the period under examination, the winds coming from the northern sector are in general more frequent than the southern sector winds with the exception of early spring and late summer period (April, May and June), where on average the southern winds are 1.5 times more frequent than the northern winds, resulting in a deterioration of the atmospheric dispersion conditions during this period when compared with the following warm months, especially July and August, during which the northern winds are more than a factor of two frequent than the southern winds.

Based on the results presented above, it can be easily noticed that Patission is certainly the most polluted station of the network, for all primary pollutants. It would be useful for the examination of the spatial distribution of air pollutants to take

Table 2: Ratios of global averages of the period 1987-1997 of the principal air pollution stations in Athens

\begin{tabular}{|c|c|c|}
\hline & Athinas/Patission & Piraeus/Patission \\
\hline $\mathrm{CO}$ & 0.61 & 0.58 \\
\hline $\mathrm{NO}_{\mathrm{X}}$ & 0.58 & 0.47 \\
\hline $\mathrm{SO}_{2}$ & 0.66 & 0.83 \\
\hline $\mathrm{BS}$ & 0.41 & 0.41 \\
\hline
\end{tabular}

this station as a reference and compare its average concentrations with the pollution levels of Athinas and Patission. The results are given in Table 2. In general, the primary pollution measured in Athinas is $60-65 \%$ of that in Patission, except for BS which is only $40 \%$. In Piraeus the ratio is more variable, ranging from $40 \%$ for BS to $83 \%$ for $\mathrm{SO}_{2}$. This significantly higher value must be attributed to the influences of the industrial activity and that of the port, as mentioned earlier. It is remarkable to note the low ratio of BS in both stations (0.4) in comparison to the ratios of $\mathrm{CO}$ and $\mathrm{NO}_{\mathrm{X}}(0.5-0.6)$, given that the main source of all three mentioned pollutants is traffic. A possible reason would be the different physical nature of this particulate pollutant in contrast to the other gaseous pollutants, which makes it to be affected more significantly from the nearby intense pollution sources (like heavy street-traffic). The fact that Patission is a street canyon may

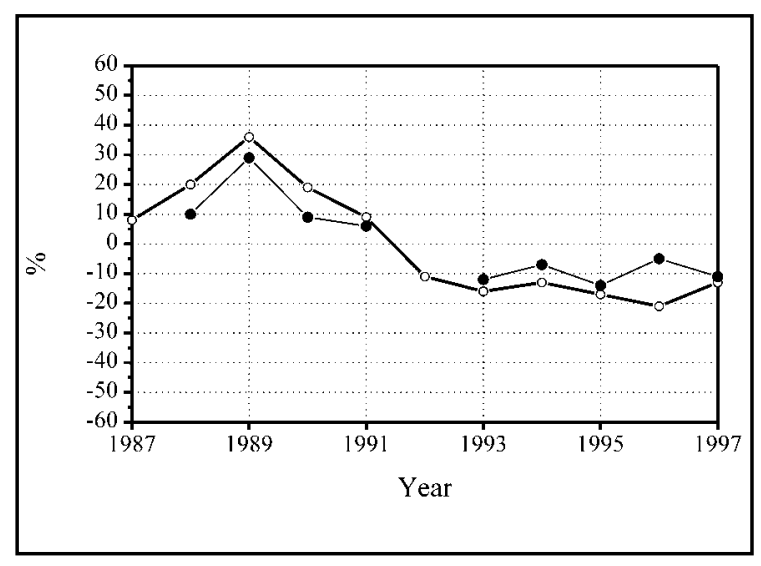

Figure 8. Deviations from the 11-year average of $\mathrm{CO}$ for the stations of Patission (bold solid line) and Athinas (solid line)

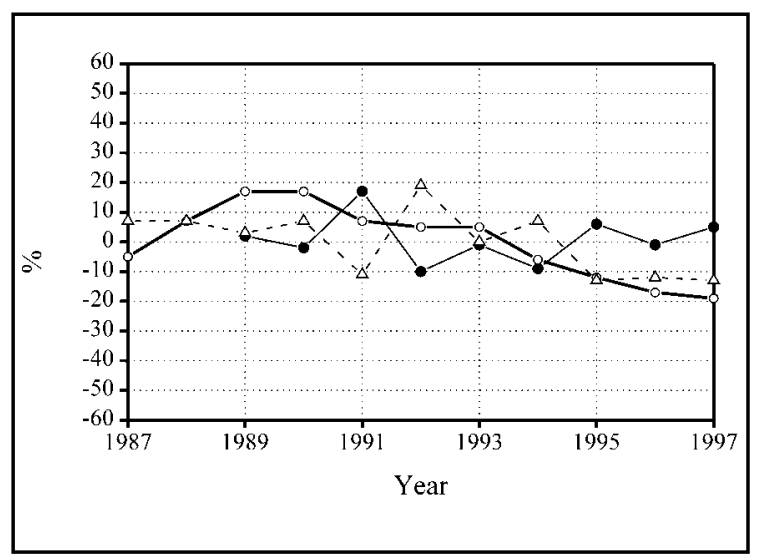

Figure 9. Deviations from the 11-year average of $\mathrm{NO}_{\mathrm{x}}$ for the stations of Patission (bold solid line), Athinas (solid line) and Piraeus (dashed line)

have also a significant influence due to the recirculation of particulates.

In order to examine the evolution of the pollution levels during this 11-year period in an homogenous manner, the percentage deviations of the yearly averages from the 11-year average were used. Using this approach the variations for each substance at any station can be directly compared to each other. In figures $8,9,10,11$ the evolution of the primary pollution in Athens is presented. For CO a clear decrease is observed between 1990-1993 for both stations, which coincides with the period of replacement of old technology cars. The reduction in Patission is more important than in Athinas (fig. 8) but it is clear 


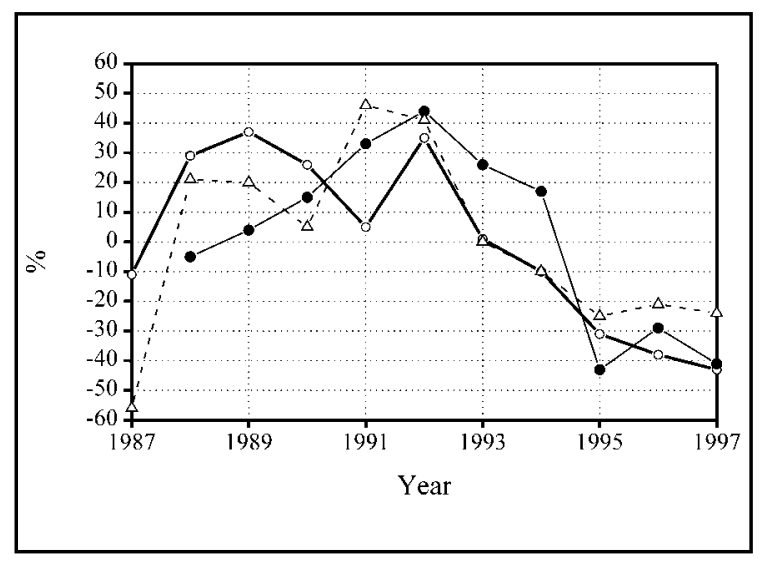

Figure 10. Deviations from the 11-year average of $\mathrm{SO}_{2}$ for the stations of Patission (bold solid line), Athinas (solid line) and Piraeus (dashed line)

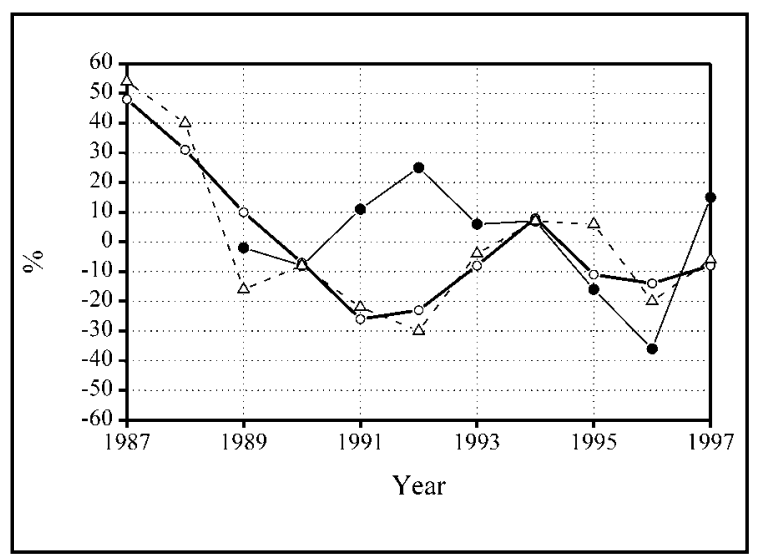

Figure 11. Deviations from the 11-year average of BS for the stations of Patission (bold solid line), Athinas (solid line) and Piraeus (dashed line)

that this pollution abatement action has influenced significantly both stations. The $\mathrm{CO}$ values in Piraeus were not used in the examination of the evolution of the pollution levels, because in the middle of this period important changes in car traffic in the vicinity of the station have been made (the nearby street is cut from the circulation and transformed into a parking place). This way the interannual variation is not representative of the temporal change of the emission pattern of a wider urban area.

The interannual variation of $\mathrm{NO}_{\mathrm{X}}$ is less marked and less uniform than that of CO. Patission shows a slight decrease after 1993 and Piraeus after 1994 of the order of $20 \%$. In Athinas the lev- els remained practically unchanged. The insignificant decrease of $\mathrm{NO}_{\mathrm{X}}$ in comparison to $\mathrm{CO}$ may be explained in terms of the lower efficiency of the car catalysers in eliminating $\mathrm{NO}_{\mathrm{X}}$ in vehicle exhausts than CO (Samaras et al., 1997).

For BS the stations of Patission and Piraeus show a similar pattern with a sharp characteristic decrease between 1987 and 1992 of the order of $70 \%$ and quite variable for the rest of the period. Athinas does not follow, probably because during the period 1991-1993 there was a large construction work close to the station.

For $\mathrm{SO}_{2}$ there is a constant decrease in all stations between 1992 and 1995 of the order of $70 \%$. The concentrations in the last three years remained stable. The pollution abatement measures taken by the state are also the main reason for the substantial reduction of $\mathrm{SO}_{2}$ atmospheric concentrations, and more precisely for the reduction of the sulfur content in diesel oil for heating and transportation purposes. The sulfur content in diesel oil was reduced in 1994 from $0.3 \%$ per weight to $0.2 \%$, while in 1996 the sulfur content in the diesel oil used for transportation was further reduced to $0.05 \%$ (MinEnv report, 1998b).

For comparison purposes, figure 12 shows the interannual variation of the yearly averages of the frequency of occurrence of northern and southern winds (data of the National Observatory of Athens). In general, the variations of the yearly averages were within $\pm 10 \%$ of the total average, except in the years 1990 and 1991, showing that the average wind conditions in Athens do not vary significantly from year to year if compared to the corresponding variations in the concentration levels of atmospheric pollutants. The absence of radical changes in the meteorological conditions from year to year is also shown in figure 13 , where the corresponding figures of sunshine duration and air temperature are presented. The maximum deviation of the mean for sunshine duration is $8 \%$, while for temperature is $5 \%$.

Concerning the contribution of the urban emissions of air pollutants to their atmospheric concentrations it has to be reminded that the most important source of the majority of primary pollutants under consideration is road traffic, from which gasoline-powered private passenger cars are by far the most important (Viras and Siskos, 1992; MinEnv report, 1989). There is a rapid evolution in the number of private cars in 
Table 3: Comparison of 3-year yearly averages of primary pollution levels

\begin{tabular}{|c|c|c|c|c|}
\hline Patission & $\mathrm{CO}\left(\mathrm{mg} / \mathrm{m}^{3}\right)$ & $\mathrm{NO}_{\mathrm{X}}\left(\mu \mathrm{g} / \mathrm{m}^{3}\right)$ & $\mathrm{SO}_{2}\left(\mu \mathrm{g} / \mathrm{m}^{3}\right)$ & $\mathrm{BS}\left(\mu \mathrm{g} / \mathrm{m}^{3}\right)$ \\
\hline $1988-1990$ & $7.7 \pm 0.6$ & $422 \pm 22$ & $83 \pm 4$ & $124 \pm 22$ \\
\hline $1995-1997$ & $5.1 \pm 0.3$ & $312 \pm 12$ & $40 \pm 4$ & $99 \pm 3$ \\
\hline change (in \%) & -33.7 & -26.1 & -51.8 & -20.1 \\
\hline & & & & \\
\hline Athinas & $\mathrm{CO}\left(\mathrm{mg} / \mathrm{m}^{3}\right)$ & $\mathrm{NO}_{\mathrm{X}}\left(\mu \mathrm{g} / \mathrm{m}^{3}\right)$ & $\mathrm{SO}_{2}\left(\mu \mathrm{g} / \mathrm{m}^{3}\right)$ & $\mathrm{BS}\left(\mu \mathrm{g} / \mathrm{m}^{3}\right)$ \\
\hline $1988-1990$ & $4.4 \pm 0.4$ & $217 \pm 7$ & $42 \pm 4$ & $44 \pm 2$ \\
\hline $1995-1997$ & $3.4 \pm 0.2$ & $224 \pm 7$ & $25 \pm 3$ & $41 \pm 12$ \\
\hline change (in \%) & -22.7 & 3.2 & -40.4 & -6.8 \\
\hline & & & & $\mathrm{BS}\left(\mu \mathrm{g} / \mathrm{m}^{3}\right)$ \\
\hline Piraeus & $\mathrm{CO}\left(\mathrm{mg} / \mathrm{m}^{3}\right)$ & $\mathrm{NO}_{\mathrm{X}}\left(\mu \mathrm{g} / \mathrm{m}^{3}\right)$ & $\mathrm{SO}_{2}\left(\mu \mathrm{g} / \mathrm{m}^{3}\right)$ & $48 \pm 14$ \\
\hline 1988 -1990 & $4.4 \pm 0.3$ & $182 \pm 4$ & $59 \pm 4$ & $42 \pm 6$ \\
\hline 1995 -1997 & $2.4 \pm 0.2$ & $150 \pm 1$ & $39 \pm 1$ & -12.5 \\
\hline change (in $\%)$ & -45.5 & -17.5 & -33.8 & \\
\hline
\end{tabular}

Athens (MinEnv report, 1998b) and a steady increasing rate with a $50 \%$ increase in total car numbers recorded in 8 years (1989-1997). The new registered cars, after 1989, were all equipped with a catalyst, but in 1997 the old technology cars were still the majority, although both percentages were approaching $50 \%$. It has to be mentioned though that cars equipped with a catalyst emit 8 to 12 times less $\mathrm{CO}$ and 3 to 6 times less $\mathrm{NO}_{\mathrm{X}}$, depending on the catalyst type used (EC 91/411 or EC 94/12), in comparison to the conventional technology cars (Samaras et al., 1997). This is the basic reason why the important increase in car numbers is not associated with a corresponding increase in the atmospheric levels of the examined pollutants. The catalyst performance can also explain the clear decrease in $\mathrm{CO}$ atmospheric levels, since the gasoline passenger car fleet is by far the most significant pollution source of $\mathrm{CO}$. Except from the poor catalyst performance, another reason for the persistence of $\mathrm{NO}_{\mathrm{X}}$ concentrations in relatively high levels is that a significant part of $\mathrm{NO}_{\mathrm{X}}$ emissions comes from diesel vehicles, which remained unaffected by the pollution abatement action. It should be also underlined that in 1997 the CO traffic emissions are still essentially determined by the conventional technology passenger cars, which are responsible for an important part of $\mathrm{NO}_{\mathrm{X}}$ emissions.

In order to make a more precise estimate of the change in the levels of urban air pollution in Athens, before and after the period of pollution abatement measures, the three-year averages
1988-1990 and 1995-1997 were compared for primary pollutants. The results are presented in Table 3. The maximum reduction is observed for $\mathrm{SO}_{2}$ with $52 \%$ in Patission followed by $40 \%$ in Athinas. The reduction in Piraeus is smaller $(34 \%)$ but it should be kept in mind the existence of extra sources in its vicinity. The next considerable reduction is observed for CO with $45 \%$ in Piraeus, 34\% in Patission and 23\% in Athinas. The very large reduction observed in Piraeus should be taken into account only qualitatively, due to traffic changes around this station mentioned earlier. The $\mathrm{NO}_{\mathrm{X}}$ levels show a decrease of $26 \%$ and $18 \%$ in Patission and Piraeus respectively, but an increase of $3 \%$ in Athinas. Finally, the BS shows a similar behavior with $\mathrm{NO}_{\mathrm{X}}$ with an important decrease in Patission and Piraeus $(20 \%$ and $12 \%$, respectively) but a smaller decrease in Athinas. In general, the improvement of the air quality in the station of Athinas is less significant than in Patission. This probably had to do with important circulation rearrangements in the commercial area situated in the vicinity of the Athinas station. The so-called "commercial triangle" became a pedestrian zone and the station of Athinas is located just outside, where the circulation should have been increased. For this reason, the magnitude of pollution reductions in Patission should be more representative of the central urban area of Athens. In general, the extent of the decrease of pollution levels is significant, because in most cases the standard deviations of the three-year averages are considerably less than the differ- 


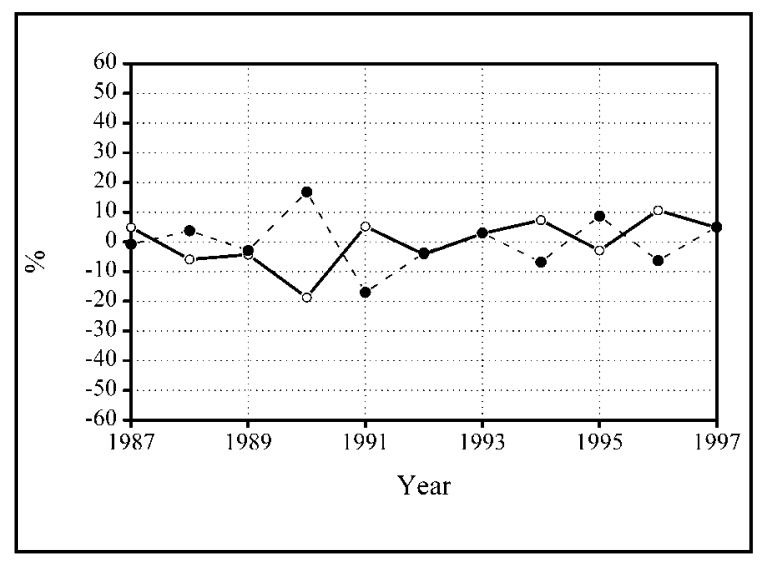

Figure 12. Deviations from the 11-year average of the frequency of appearance of northern (bold solid line) and southern (dashed line) winds in Athens

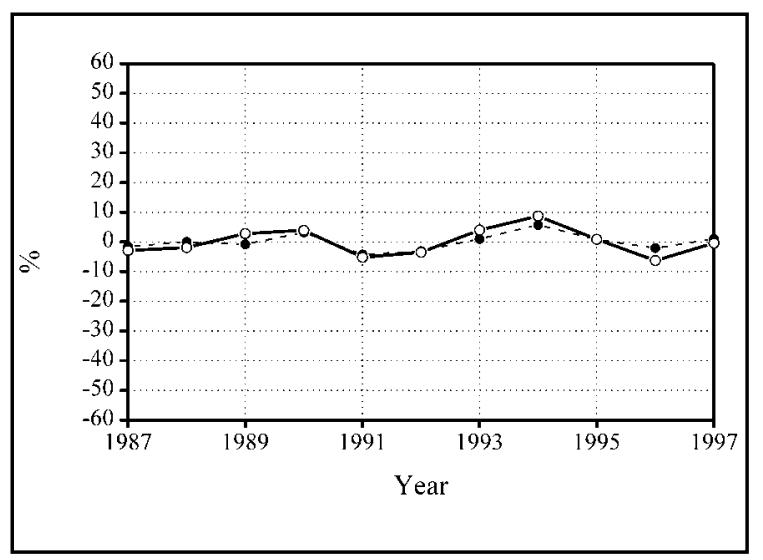

Figure 13. Deviations from the 11-year average of temperature (dashed line) and sunshine duration (bold solid line) in Athens

ences between the two average values, while they are statistically significant, with the exception of $\mathrm{BS}$ in all stations and $\mathrm{NO}_{\mathrm{X}}$ in Athinas.

From the above table and also from figures 813 , it can be argued that there are strong indications that the important decreases in the pollution levels observed for all pollutants should be mainly determined by the changes in the emission patterns. An important reason is that the changes are highly variable between stations and between pollutants, while if dispersion conditions were the primary cause of changes, they should have been more uniform. Additionally, the decrease in $\mathrm{CO}$ concentrations happened exactly in the period of old technology car replacement (1990-1992), and its extent is close to the expected decrease in emis- sions (about 30\%). At the same time, the corresponding $\mathrm{SO}_{2}$ concentrations, which were not affected by the measure, have been increased. A similar argument could be used for the significant decrease observed for $\mathrm{SO}_{2}$ in 1993-1994, which coincides with the reduction of sulfur content in diesel oil. In this case, the corresponding CO concentrations, also unaffected by this action, have been slightly increased.

It is difficult to attribute to the meteorological factor decreases of the order of $40-50 \%$ in the average yearly concentration levels, while the corresponding changes for meteorological parameters rarely exceed $10 \%$. But on the other hand, it should be remembered that all the above are only rough estimations, and it must be emphasized that the influence of the meteorological parameters on the atmospheric pollution levels is a quite complex phenomenon and its quantification requires detailed studies for shorter time-scales, which goes beyond the scope of this paper. In order to obtain a precise estimation of the role of meteorology in the evolution of pollution levels, a detailed investigation on a daily or even hourly basis of some key meteorological factors should be carried out: wind parameters (at the surface as well as at higher levels), vertical stability of the atmosphere, solar radiation and air temperature.

Concerning exceeding the air quality standards, the interannual variation of 8 -h periods exceeding $10 \mathrm{mg} / \mathrm{m}^{3}$ for $\mathrm{CO}$ will be first examined (MinEnv report, 1998a). CO is a good indicator of primary pollution, since in Athens the basic pollution source is traffic and the most characteristic pollutant from traffic is CO. While in the period 1988-1990 exceeding the limits were between 22$27 \%$ in the last 3 years of the period examined is dropped to $3-7 \%$. At the same time in Athinas exceeding the limits of $\mathrm{CO}$ vary between $1-2 \%$ and in Pireus are almost zero. Concerning the other pollutants there are still problems for the $\mathrm{NO}_{2}$ in Patission, where the limit of $200 \mu \mathrm{g} / \mathrm{m}^{3}$ (98 percentile of hourly values in a year) is slightly exceeded. In the same station there are problems with BS as the yearly median of $80 \mu \mathrm{g} / \mathrm{m}^{3}$ is exceeded the last years by about $20 \%$, while in the other two stations the yearly median in recent years is about half of the limit. Finally, for $\mathrm{SO}_{2}$ the pollution levels at the main stations of the urban air pollution network are well below any limits (MinEnv report, 1998a). 
Therefore, despite the significant improvement in the levels of primary pollutants in Athens during the last decade, in order to have full compliance with the air quality standards further pollution abatement measures should be taken, especially concerning car emissions. The emphasis should be put first on replacing the old technology gasoline-powered private cars, which will remain the most significant polluters given that the performance of the catalysts is constantly improving (Samaras et al., 1997). A pollution abatement plan against traffic emissions becomes more urgent if it is taken into account that the main air quality problem in Athens is photochemical pollution (MinEnv report, 1998a; Kalabokas et al., 1999) and the most appropriate action should be the substantial reduction of hydrocarbons, which come mainly from the private passenger car fleet (Ziomas et al., 1998). Finally, the persistence of black smoke concentrations at relatively high levels, especially in Patission, makes also necessary another intervention from the state authorities towards emission reductions from diesel-powered vehicles, mainly taxis and public transportation buses.

\section{CONCLUSIONS}

From the three central most polluted urban stations in Athens, Patission is undoubtedly the most polluted one for all primary pollutants, followed by Athinas and Piraeus.

For all examined pollutants a strong seasonal variation is observed with maxima in winter months and minima in summer months. The curves of $\mathrm{CO}$ and $\mathrm{NO}_{\mathrm{X}}$ show quite the same pattern, indicating major influence from the same source (car traffic). The average winter levels are by about $50-70 \%$ higher than the summer ones. $\mathrm{SO}_{2}$ has the most considerable seasonal variation, and the average winter/summer ratio is greater than a factor of two in Patission, while black smoke shows the least marked seasonal cycle with winter average values only $20-30 \%$ higher than the summer ones.

For $\mathrm{CO}$ a clear decrease in the average annual concentrations is observed between 1990-1993 for the stations of Athinas and Piraeus, which coincides with the period of replacement of old technology cars, while the interannual variation of $\mathrm{NO}_{\mathrm{X}}$ is less marked and less uniform than that of CO. For BS the stations of Patission and Piraeus show a similar pattern with a sharp characteristic decrease from 1987 to 1992 . For $\mathrm{SO}_{2}$ there is a sharp decrease in all stations from 1992 to 1995.

For the three-year averages between 19881990 and 1995-1997, the maximum reduction is observed for $\mathrm{SO}_{2}$ followed by $\mathrm{CO}$.

If the changes in the emission and meteorological parameters are considered in parallel, it can be argued that the considerable decreases in the pollution levels observed for all pollutants are mainly due to changes in the emission patterns and not in meteorology.

Exceeding the limits in air quality standards for CO in the period 1988-1990 was between $22-27 \%$, while in the last 3 years of the period examined (1995-1997) this dropped to 3-7\%. Regarding the other pollutants there are still problems for the $\mathrm{NO}_{2}$ and $\mathrm{BS}$ in Patission.

Therefore, despite the significant improvement in the levels of primary pollutants in Athens during the last decade, in order to have full compliance with the air quality standards further measures should be taken especially concerning traffic emissions. The emphasis should be put first on replacing the old technology gasoline-powered private cars, which are the most significant polluters for some primary pollutants, and at the same time important emission sources of photochemical precursors.

\section{BIBLIOGRAPHY}

Alexopoulos, A. D. Assimacopoulos, and E. Mitsoulis (1993). Model for traffic emissions estimation, Atmosph. Environ. 27B, 435-446

Arvanitis, Th., Th. Nitis, G. Theodoridis, P. M. Tourlou, Ch. Naneris and N. Moussiopoulos (1997). Synthesis of the 2004 emission inventory for Athens, Proceedings of the International Scientific Workshop Athens 2004 Air Quality Study, pp. 60-68, Athens, Greece

Finlayson-Pitts B. and Pitts J. Jr, (1986). Atmospheric Chemistry: Fundamentals and Experimental Techniques. J. Wiley New York

Kalabokas, P.D., L. G. Viras, C. C. Repapis, J. G. Bartzis (1999). Analysis of the 11-year record (1987-1997) of air pollution measurements in Athens, Greece. Part II: Photochemical pollutants. Global Nest: The 
International Journal, 1, 169-176

Kallos, G., P. Kassomenos and Pielke R.A. (1993). Synoptic and mesoscale weather conditions during air pollution episodes in Athens, Greece. Bound. Layer Meteorol., 62, 163-184

Kassomenos, P., V. Kotroni and G. Kallos (1995). Analysis of climatological and air quality observations from Greater Athens area. Atmos. Environ., 29, 3671-3688

Katsoulis, B. D. (1996). The relationship between synoptic, mesoscale and microscale meteorological paramters during poor air quality events in Athens, Greece. The Science of the Total Environment, 181, 13-24

Lalas, D, M. Tombrou-Tsella, M. Petrakis, D. Asimakopopulos and C. Helmis, (1987). An experimental study of the horizontal and vertical ozone distribution over Athens. Atmos. Environ., 21, 2681-2693

Mantis, O., C. Repapis, C. Zerefos and J. Ziomas (1992). Assessment of the potential for photochemical air pollution in Athens: A comparison of emissions and air pollutants in Athens with those in Los Angeles. $J$. Appl. Met., 31, 1467-1476

MinEnv report (1989). Atmospheric pollution in the Athens area. Technical report. 2. Pollution sources. Directorate of air pollution and noise control, Ministry of Environment (in Greek)

MinEnv report (1998). Atmospheric pollution in Athens - 1997. Directorate of air pollution and noise control, Ministry of Environment (in Greek)

MinEnv report (1998b). Attiki-SOS. Atmospheric pollution in Athens, 1994-1997. Ministry of Environment (in Greek)

Paliatsos, A. (1998). The seasonal and diurnal variation of sulfur dioxide in Greater Athens area, Greece. Fres. Envir. Bull., 7, 539-550

Prezerakos, N.G. (1986). Characteristics of the Sea-breeze in Attica, Greece. Boundary-Layer Meteorology 36, 245-266

Repapis, C.C., Zerefos C.S. and Tritakis B. (1975). On the Etesians over the Aegean. Proc. Acad. Athens, 52, 572606

Samaras, Z., Andrias A., Zachariadis T. and Aslanoglou M. (1997). Forecast of road traffic emissions for the Greater Athens area. Proceedings of the International Scientific Workshop Athens 2004 Air Quality Study, 39-50, Athens, Greece

Viras, L. and P. Siskos (1992). Air pollution by gaseous pollutants in Athens, Greece. In: Gaseous pollutants: Characterization and Cycling, Edited by J.O. Nriagu, J. Wiley, 271-305

Ziomas, I., P. Suppan, B. Rappengluck, D. Balis P. Tzoumaka, D. Melas, A. Papayiannis, P. Fabian and C. Zerefos, (1995). A contribution to the study of photochemical smog in the Greater Athens area. Beitr. Phys. Atmosph. 68, 191-203

Ziomas, I. C., Tzoumaka B., Balis D., Melas D., Zerefos C., and Klemm O. (1998). Ozone episodes in Athens, Greece. A modelling approach using data from the MEDCAPHOT-TRACE, Atmos. Environ., 32, 2313-2322 